\title{
Prognostic Significance of Acute Systolic Hypertension after Myocardial Infarction
}

\author{
K. M.FOX, \\ I. W. TOMLINSON, \\ R. W. PORTAL, \\ CLIVE P. ABER
}

British Medical fournal, 1975, 3, 128-130

Patients with systolic blood pressures between $151-169 \mathrm{~mm} \mathrm{Hg}$ were excluded since we considered these levels to be "borderline" in this age range. Patients with systolic blood pressures less than $150 \mathrm{~mm} \mathrm{Hg}$ but with initial diastolic blood pressures of over $100 \mathrm{~mm} \mathrm{Hg}$ were also excluded because we thought that some of them were likely to be longstanding undetected hypertensive subjects with reduced ("clipped") systolic blood pressures after acute myocardial infarction.

The blood pressure was measured on admission and 30 minutes later. Thereafter recordings were made every four hours for the first 72 hours and then six hourly for the remainder of the patients' stay in hospital unless there was an indication for making more frequent measurements.

The diagnosis of acute anterior and posterior myocardial infarction was based on the electrocardiographic (E.C.G.) criteria of the World Health Organization. ${ }^{5}$ The recommendations of Perloff were used to define "true" posterior infarction. ${ }^{6}$ When the site of infarction was obscured by pre-existing E.C.G. abnormalities (previous myocardial infarction or left bundle branch block or both) recent infarction was diagnosed on the basis of a characteristic history, a raised peak serum aspartate aminotransferase (SGOT) level, a typical temperature curve, and a raised sedimentation rate.

E.C.G.s were performed on each of the first three days of the patients' stay in the coronary care unit and weekly thereafter unless there was an indication for obtaining further records. SGOT was estimated daily for at least the first three days then weekly. Measurements were made by a modified spectrophotometric method using a reaction rate analyser. The SGOT was considered abnormal if $10 \%$ above the laboratory's upper limit of normal of $22 \mathrm{IU} / 1$.

The subsequent inpatient progress of both groups was examined to obtain data on (a) the peak SGOT; $(b)$ the incidence of major arrhythmias (ventricular tachycardia, ventricular fibrillation, asystole, and complete heart block), sinus tachycardia ( $\geqslant 100$ beats/min), and sinus bradycardia ( $<60$ beats $/ \mathrm{min}) ;(c)$ the development of left heart failure, defined as radiological pulmonary oedema. Lesser degrees of pulmonary oedema were excluded as observer error here is high; $(d)$ mortality rate; and $(e)$ the presence of glycosuria. Urine was tested routinely in all patients on admission. Where glycosuria was found a glucose tolerance test was performed before discharge from hospital.

In the systolic hypertensive group the duration of hypertension was recorded both from the time of admission and from the onset of the most severe chest pain (estimated time of infarction). All the surviving patients were seen at least once at outpatient follow-up and their blood pressure recorded. The number of patients who were then hypertensive (systolic pressure greater than $170 \mathrm{~mm} \mathrm{Hg}$ and a diastolic pressure greater than $100 \mathrm{~mm} \mathrm{Hg}$ ) was noted.

The data were analysed statistically using the $\chi^{2}$ test for two independent samples, the Fisher exact probability test, and the $t$ test for independent samples.

the coronary care unit, Kingston General Hospital, Hull, between January 1972 and December 1974106 patients ( 87 men and 19 women) had a raised systolic blood pressure on admission without a history of established hypertension (systolic hypertensive group). We defined a raised systolic blood pressure as a pressure of $170 \mathrm{~mm} \mathrm{Hg}$ or more which persisted for at least 30 minutes. In all patients the blood pressure fell to less than $150 \mathrm{~mm} \mathrm{Hg}$ within 72 hours. The diastolic blood pressure was considered to be raised when its initial value was $100 \mathrm{~mm} \mathrm{Hg}$ or more (recorded at the fourth sound of Korotkow). The first 106 patients admitted with acute myocardial infarction from January 1973 with systolic blood pressures between $120-150 \mathrm{~mm} \mathrm{Hg}$ and diastolic blood pressures less than $<100 \mathrm{~mm} \mathrm{Hg}$ on admission were selected as controls. None of these patients had established hypertension.

Department of Cardiology, Kingston General Hospital, Hull HU3 IUR

K. M. FOX, M.B., M.R.C.P., Registrar

I. W. TOMLINSON, M.B., B.S., Registrar

R. W. PORTAL, M.D., F.R.C.P., Consultant Physician

CLIVE P. ABER, M.D., F.R.C.P., Consultant Physician

\section{Results}

The two groups-106 patients with acute systolic hypertension (systolic hypertensive group) and 106 normotensive controls-were well matched in mean age and sex and medical and cardiovascular history (see table I), duration of chest pain, and the time between the onset of the most severe pain and admission (table II). The incidence of anterior and inferior infarctions was also similar (table I).

The mean peak SGOT levels were significantly higher in the systolic hypertensive group $(P<0.001 ;$ table III). When the two groups were compared according to the site of infarction this finding was still evident $(P<0.005)$. In the systolic hypertensive group patients with initial systolic blood pressure levels over $200 \mathrm{~mm} \mathrm{Hg}$ had similar mean peak SGOT levels ( \pm S.D.) to those whose initial systolic blood pressures were between 170 and $200 \mathrm{~mm} \mathrm{Hg}(239 \pm 142 \mathrm{IU} / 1$ and $254 \pm 131 \mathrm{IU} / 1$ respectively). When the systolic blood pressure returned to below $170 \mathrm{~mm} \mathrm{Hg}$ within four hours the peak SGOT level was significantly lower than when the blood pressure was raised for more than 12 hours whether the duration of systolic hypertension 
TABLE I-Cardiac History, Site of Myocardial Infarction, and Outcome in Systolic Hypertensive and Control Groups. Results are Numbers of Patients

\begin{tabular}{|c|c|c|c|c|c|c|c|c|c|c|}
\hline & \multirow{2}{*}{$\begin{array}{l}\text { Mean Age } \\
\text { ( } \pm \text { S.D.) } \\
\text { (Years) }\end{array}$} & \multicolumn{2}{|c|}{ Sex } & \multicolumn{2}{|c|}{ Cardiac History } & \multicolumn{2}{|c|}{ Site of Infarction* } & \multicolumn{3}{|c|}{ Outcome } \\
\hline & & M. & F. & $\begin{array}{l}\text { Previous } \\
\text { Myocardial } \\
\text { Infarction }\end{array}$ & $\begin{array}{l}\text { Previous } \\
\text { Angina } \\
\text { Only }\end{array}$ & Anterior & Inferior & Deaths & $\begin{array}{c}\text { Major } \\
\text { Arrhythmias }\end{array}$ & $\begin{array}{l}\text { Cardiac } \\
\text { Failure }\end{array}$ \\
\hline $\begin{array}{l}\text { Systolic hypertensive group } \\
\text { Control group }\end{array}$ & $\begin{array}{l}58 \pm 10 \\
57 \pm 10\end{array}$ & $\begin{array}{l}87 \\
81\end{array}$ & $\begin{array}{l}19 \\
25\end{array}$ & $\begin{array}{l}19 \\
20\end{array}$ & $\begin{array}{l}12 \\
18\end{array}$ & $\begin{array}{l}52 \\
55\end{array}$ & $\begin{array}{l}54 \\
51\end{array}$ & $\begin{aligned} & 13(12 \%) \\
& 2(2 \%)\end{aligned}$ & $\begin{array}{c}22(21 \%) \\
5(5 \%)\end{array}$ & $\begin{array}{l}35(33 \%) \\
10(9 \%)\end{array}$ \\
\hline
\end{tabular}

*True posterior infarction was not observed.

TABLE II-Duration of Chest Pain from Estimated Time of Acute Myocardial Infarction and Time between Onset of Chest Pain and Admission to Coronary Care Unit in Systolic Hypertensive and Control Groups. Results are Numbers of Patients

\begin{tabular}{l|c|c|c|c|c|c|c|c}
\hline & \multicolumn{3}{|c|}{$\begin{array}{c}\text { Duration of Chest Pain } \\
(\mathrm{h})\end{array}$} & \multicolumn{2}{c}{$\begin{array}{c}\text { Time before Admission } \\
(\mathrm{h})\end{array}$} \\
\cline { 2 - 7 } & $<\frac{1}{2}$ & $\frac{1}{2}-2$ & $>2-4$ & $>4$ & $<4$ & $4-12$ & $>12$ \\
\hline Systolic hypertensive & 8 & 24 & 41 & 33 & 40 & 49 & 17 \\
group & 3 & 23 & 40 & 40 & 38 & 52 & 16 \\
\hline
\end{tabular}

TABLE III-Mean Peak SGOT Levels ( \pm S.D.) (IU/l) after Acute Myocardial Infarction in Systolic Hypertensive and Control Groups

\begin{tabular}{l|c|c|c}
\hline & $\begin{array}{c}\text { Anterior } \\
\text { Infarction }\end{array}$ & $\begin{array}{c}\text { Inferior } \\
\text { Infarction }\end{array}$ & $\begin{array}{l}\text { Mean Value for } \\
\text { Whole Group }\end{array}$ \\
\cline { 1 - 3 } $\begin{array}{l}\text { Systolic hypertensive } \\
\text { group }\end{array}$ & $285 \pm 147$ & $218 \pm 106$ & $251 \pm 131$ \\
\begin{tabular}{l} 
Control group \\
\hline
\end{tabular} & $207 \pm 127$ & $164 \pm 97$ & $186 \pm 114$ \\
\hline
\end{tabular}

was measured from the time of admission to hospital $(P<0.05)$ or from the estimated time of infarction $(P<0.025$; table IV). Within the systolic hypertensive group neither the level nor the duration of the initial diastolic blood pressure (table V) correlated with either subsequent clinical behaviour or mean peak SGOT level.

TABLE IV-Relation between Mean Peak SGOT ( \pm S.D.) (IU/l) and Duration of Hypertension as Measured from Time of Admission and Estimated Time of Infarction. Numbers of Patients are Given in Parentheses

\begin{tabular}{l|c|c|c}
\multicolumn{1}{c|}{ Duration of hypertension: } & $<4 \mathrm{~h}$ & $4-12 \mathrm{~h}$ & $>12 \mathrm{~h}$ \\
\hline $\begin{array}{l}\text { From time of admission } \\
\text { From time of infarction }\end{array}$ & $221 \pm 129(33)$ & $245 \pm 118(43)$ & $292 \pm 159(30)$ \\
\hline
\end{tabular}

TABLE V-Relation between Mean Peak SGOT ( \pm S.D.) $(I U / l)$ and Level of Diastolic Blood Pressure in Systolic Hypertensive Group after Acute Myocardial Infarction. Numbers of Patients are Given in Parentheses

\begin{tabular}{l|c|c|c}
\hline $\begin{array}{l}\text { Diastolic blood pressure (mm Hg) } \\
\text { Mean peak SGOT }\end{array}$ & $\begin{array}{c}<100 \\
238 \pm 110(13)\end{array}$ & $253 \pm 130(80)$ & $249 \pm 118$ (13) \\
\hline
\end{tabular}

The mortality, incidence of major arrhythmias, and, incidence of cardiac failure in the systolic hypertensive group were greater than in the control group $(\mathrm{P}<0.01, \mathrm{P}<0.001$, and $\mathrm{P}<0.001$ respectively; see table I). The clinical progress and mean peak SGOT levels of the 12 patients in the systolic hypertensive group and the six in the control group who were in cardiac failure on admission did not differ significantly from those of their respective groups as a whole.

Glycosuria was found in 24 patients in the systolic hypertensive group and three patients in the control group $(\mathrm{P}<0.001)$. The glycosuria was transient in 23 patients. Two patients in each group were subsequently found to have diabetic glucose tolerance curves.

The clinical behaviour and peak SGOT levels were similar in patients who displayed either an initial sinus tachycardia $(\geqslant 100 / \mathrm{min})$ or sinus bradycardia $(<60 / \mathrm{min})$ in both groups.

At outpatient follow-up $13(14 \%)$ of the 93 survivors from the systolic hypertensive group had a diastolic blood pressure of $100 \mathrm{~mm}$ $\mathrm{Hg}$ or more and a systolic pressure of $170 \mathrm{~mm} \mathrm{Hg}$ or more. The hospital progress of these patients had not differed significantly from that of the systolic hypertensive group as a whole.

\section{Discussion}

The prognostic significance of an initially raised systolic blood pressure after acute myocardial infarction is not clear. It has been suggested that in the presence of coronary occlusion an increased arterial blood pressure may play a protective part by increasing coronary perfusion. ${ }^{8}{ }^{\circ}$ Conversely, by increasing ventricular wall tension and thereby myocardial oxygen demands, arterial hypertension may increase the extent of myocardial damage. ${ }^{10}$

Our results support the latter view since the mortality rate and the incidence of major arrhythmias and heart failure were greater in those patients who had initial systolic hypertension. Furthermore, the significantly higher mean peak SGOT level in this group suggests more extensive myocardial damage. ${ }^{11} 12$ The direct correlation between the duration of systolic hypertension and the mean peak SGOT values also implies increasing myocardial damage in the presence of persistently raised systolic blood pressure. The alternative interpretation-that the rise in blood pressure after acute myocardial infarction is merely an expression of an initially large infarct-would, therefore, seem less likely, especially as the duration of chest pain was similar in both groups.

A raised blood pressure after acute myocardial infarction is usually attributed to increased catecholamine release, ${ }^{4}$ and this may have accounted for the high incidences of glycosuria and major arrhythmias in our non-diabetic patients. ${ }^{13}$

After acute myocardial infarction jeopardized myocardial tissue may be potentially salvageable for several hours if the myocardial oxygen supply is increased or the demand reduced. ${ }^{14}$ Several therapeutic programmes have been proposed in an attempt to restrict infarct size, including the use of intravenous $\beta$-blockade, ${ }^{15}$ nitroglycerin, ${ }^{16}$ immediate myocardial revascularization, ${ }^{17}$ and both external and intra-aortic balloon counter pulsation. ${ }^{18} 19$

Promising results have also been obtained using hypotensive treatment to reduce myocardial oxygen demands. Kelly et al. ${ }^{20}$ showed an apparent haemodynamic benefit from the administration of intravenous phentolamine in five patients with "acute hypertension" after myocardial infarction. They were less optimistic, however, about its use in five of their patients with established hypertension because two developed disproportionate tachycardia and recurrence of chest pain which necessitated discontinuation of hypotensive treatment. Similarly, Shell and Sobel ${ }^{10}$ using trimetaphan camsylate in a group of 14 hypertensive patients (blood pressure $145 / 90 \mathrm{~mm} \mathrm{Hg}$ ) showed that cautious reduction of blood pressure after acute myocardial infarction seemed to limit infarct size; 10 of these patients also had established hypertension. In both these studies, however, hypotensive treatment was delayed for a mean of nine and 11 hours respectively after the onset of acute symptoms. In the light of these previous reports our observations suggest that patients with a systolic blood pressure of at least $170 \mathrm{~mm} \mathrm{Hg}$ on admission may benefit from early hypotensive treatment, particularly if there is no evidence of a pre-existing hypertension. 
References

${ }^{1}$ Rosenbaum, F. F., and Levine, S. A., Archives of Internal Medicine, 1941, 68, 913.

2 Peel, A. A. F., et al., British Heart fournal, 1962, 24, 745.

3 Gazes, P. C., Richardson, J. A., and Woods, E. F., Circulation, 1959, 19, 657.

4 Siggers, D. C., Salter, C., and Fluck, D. C., British Heart fournal, 1971, 33, 878 .

5 World Health Organization, Hypertension and Coronary Heart Disease, Technical Report Series No. 168. Geneva, W.H.O., 1959.

6 Perloff, J. K., Circulation, 1964, 30, 706.

${ }^{7}$ Marrott, P., et al., British Heart fournal, 1973, 12, 1240.

${ }^{8}$ Maroko, P. R., et al., Circulation, 1971, 43, 67.
${ }^{9}$ Maroko, P. R., and Braunwald, E., Annals of Internal Medicine, 1973, 79, 720.

10 Shell, W. E., and Sobel, B. E., New England fournal of Medicine, 1974, $291,481$.

11 Lemley-Stone, J., et al., American fournal of Physiology, 1955, 183, 555.

12 Nydick, I., Wroblewski, F., and LaDue, J. S., Circulation, 1955, 12, 161.

13 Jewitt, D. E., et al., Lancet, 1969, 1, 635.

14 Sobel, B. E., and Shell, W. E., Circulation, 1973, 47, 215.

15 Mueller, H. S., et al., Circulation, 1974, 49, 1078.

${ }^{16}$ Hirshfield, J. W. et al., Circulation, 1974, 49, 291.

17 Ginks, W. R., et al., fournal of Clinical Investigation, 1972, 51, 2717.

18 Maroko, P. R., et al., Circulation, 1972, 45, 1150.

19 Messer, J. V., et al., Clinical Research, 1973, 21, 438.

20 Kelly, D. T., et al., Circulation, 1973, 47, 729.

\title{
Use of Clomiphene and Luteinizing Hormone/Follicle Stimulating Hormone-releasing Hormone in Investigation of Ovulatory Failure
}

\author{
JEAN GINSBURG， A. J. ISAACS， MARION B. R. GORE， C. W. H. HAVARD
}

British Medical fournal, 1975, 3, 130-133

\section{Summary}

A luteinizing hormone/follicle-stimulating hormonereleasing hormone (LH/FSH-RH) test was performed in 70 women with amenorrhoea or anovulatory infertility, or both, and a clomiphene stimulation test was also performed in 24 of these patients. Most patients responded to LH/FSH-RH with significant increases in LH and FSH. In women with gonadal dysgenesis or premature ovarian failure exaggerated responses were observed after LH/FSH-RH and there was no change in high basal LH levels after clomiphene. Patients with absent or impaired responses to LH/FSH-RH failed to respond to clomiphene. All patients with anovulatory menstrual cycles responded to both LH/FSH-RH and clomiphene, while seven out of 13 amenorrhoeic patients with a normal LH/FSH-RH response showed an early LH rise during clomiphene treatment and six were unresponsive. These results suggest a difference between the two groups at hypothalamic level with consequent therapeutic implications.

\section{Introduction}

The synthetic decapeptide luteinizing hormone/follicle-stimulating hormone-releasing hormone (LH/FSH-RH) stimulates luteinizing hormone $(\mathrm{LH})$ and follicle-stimulating hormone (FSH) release in man, ${ }^{1}$ but a $\mathrm{LH} / \mathrm{FSH}-\mathrm{RH}$ test alone cannot distinguish between hypothalamic and pituitary causes of hypogonadism. ${ }^{2}$ Since clomiphene citrate also induces a rise in gonadotrophin levels, ${ }^{3}{ }^{4}$ an effect presumed to be mediated via endogenous $\mathrm{LH} / \mathrm{FSH}-\mathrm{RH}$, a study was undertaken to determine whether by the use of both LH/FSH-RH and clomiphene

\footnotetext{
Departments of Endocrinology, Gynaecology, and Chemical Pathology, Royal Free Hospital, London NW3 2QG

JEAN GINSBURG, D.M., M.R.C.P., Consultant Endocrinologist A. J. ISAACS, B.M., M.R.C.P., Abbott Research Fellow MARION B. R. GORE, B.SC., PH.D., Principal Biochemist

C. W. H. HAVARD, D.M., F.R.C.P., Consultant Physician and Endocrinologist
}

citrate the site of dysfunction in patients with disturbed hypothalamo-pituitary-gonadal function might be established with more precision, thereby facilitating the selection of appropriate treatment.

We report here the effects of giving clomiphene to 24 out of 70 anovulatory women who had had a LH/FSH-RH test.

\section{Patients}

Seventy patients presenting with amenorrhoea (56 women aged 17-42 years) or anovulatory cycles (14 women aged 24-38 years) were studied. The cause of amenorrhoea or anovulation was investigated fully in each case; gynaecography was performed in 30 and laparoscopy in 34 women.

Twenty women had primary amenorrhoea. Gonadal dysgenesis confirmed by gynaecography or laparoscopy was present in five of these, two of whom showed chromosomal abnormalities. Laparoscopy in seven of the remaining 15 patients showed small ovaries but biopsy showed plentiful follicular tissue in five women.

Of the other 36 amenorrhoeic patients six presented with menopausal symptoms suggesting premature ovarian failure; no follicles were seen in ovarian biopsies from four, and in the other two, though occasional follicles were observed, there was no change in urinary oestrogen levels after large doses of human menopausal gonadotrophins. Amenorrhoea occurred after stopping oral contraception in seven women, after a miscarriage in one, and after delivery in one. The onset of amenorrhoea was associated with weight loss in 11 women, five of whom were considered to have anorexia nervosa; emotional factors were implicated in four other women. One woman had chronic liver disease with sclerocystic ovaries found at laparoscopy, and one suffered from intestinal malabsorption. No clear cause was apparent in the remaining four women. Of the 14 women with anovulatory cycles six had sclerocystic ovaries shown by laparoscopy or gynaecography.

LH/FSH-RH tests were performed in all 70 women and also in seven healthy women with regular menses; six of the latter were parous and all were studied in the follicular phase. Clomiphene stimulation tests were performed in 24 patients (seven with primary amenorrhoea, 12 with secondary amenorrhoea, and five with anovulatory cycles, see table).

\section{Methods}

LH/FSH-RH Test.-LH/FSH-RH (Hoechst) $100 \mu \mathrm{g}$ was given by rapid intravenous injection and venous blood samples taken at 0 , 20 , and 60 minutes. ${ }^{5}$

Clomiphene Stimulation Test.-Clomiphene citrate $\left(2 \mathrm{mg} \mathrm{kg}^{-1}\right.$ day $^{-1}$ to the nearest $50 \mathrm{mg}$ ) was given by mouth for seven days, starting on 